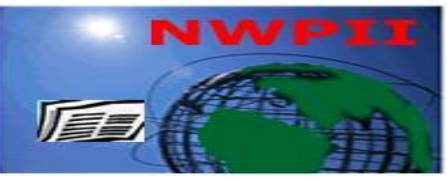

American Journal of

Biomedical Sciences

ISSN: 1937-9080

nwpii.com/ajbms

\title{
Hepatoprotective Effect of Eplerenone, A Selective Mineralocorticoid Receptor Antagonist, Against Thioacetamide Induced Liver Injury in Rats
}

\author{
Mona A. Said
}

M.D. Medical physiology, Physiology department, Faculty of Medicine, Benha University, Egypt.

Corresponding Author

Mona A. Said

Physiology department

Benha Faculty of Medicine (http://www.fmed.bu.edu.eg/)

Benha, Qalubiya

Egypt

Tel: 00201117060320

Email: dr.monaabdelazim@gmail.com

Received: 02 March 2016; | Revised: 02 April 2016; | Accepted: 13 April 2016

\begin{abstract}
A growing body of evidence suggests the contribution of aldosterone in induction of oxidative stress, endothelial dysfunction, inflammation and fibrosis in the vasculature, heart and kidney leading to progressive target organ damage. However, its role in liver injury is not clearly elucidated. The aim of this study is to investigate the effect of eplerenone, a selective mineralocorticoid receptor antagonist, on liver injury in rat and the possible underlying mechanisms. Liver injury was induced by intraperitoneal injection of thioacetamide ( $200 \mathrm{mg} / \mathrm{kg}$ body weight, 3 times per week for 4 weeks). Thioacetamide injection resulted in significant increase in serum aspartate aminotransferase, alanine aminotransferase, interleukin 6, Tumor necrosis factor alpha and hepatic malondialdehyde concomitant with significant decline in the indices of antioxidant capacity, hepatic reduced glutathione and superoxide dismutase. Treatment with eplerenone (4 $\mathrm{mg} / \mathrm{kg} /$ day for 4 weeks) in thioacetamide injected rats significantly restored these values to nearly the control values. The present study suggests implication of aldosterone in the pathophysiology of liver injury as treatment with eplerenone has hepatoprotective effect against liver injury induced by thioacetamide via reducing liver enzymes, inflammatory markers and oxidative stress.
\end{abstract}

Keywords: Eplerenone, Liver, Thioacetamide, Oxidative stress, Inflammation.

\section{Introduction}

Liver is the largest organ in the human body that has a pivotal role in maintaining homeostasis, storage of nutrients, secretory functions, excretory functions, and detoxification of drugs and chemicals [1]. Liver fibrosis and its end stage cirrhosis are significant health problem and a major cause of morbidity and mortality worldwide. Hepatic fibrosis is a dynamic condition between fibrogenesis and fibrolysis that is caused by viral hepatitis infections, alcoholism, 
autoimmune diseases, or nonalcoholic fatty liver [2]. It is characterized by progressive inflammation, involvement of hepatic stellate cells (HSCs) and Kupffer cells (KCs) with activation of proinflammatory cytokines and growth factors resulting in increased collagen, elastin, glycoprotein, and proteoglycans deposition in extracellular matrix (ECM) ending by liver dysfunction or irreversible cirrhosis [3, 4].

Experimental fibrosis can be induced by bile duct ligation (BDL) and intoxication by carbon tetrachloride $\left(\mathrm{CCl}_{4}\right)$ or thioacetamide [5]. Thioacetamide (TAA), used as a fungicide several decades ago, is a potent hepatotoxin resulting in liver injury and centrilobular necrosis [6]. It is widely used in animal models to induce liver injury which is attributed to its metabolic product [7].

There is a major need to understand the mechanisms involved in hepatic fibrosis in order to develop new therapies which can prevent or slow down the development and progression of hepatic fibrosis especially in patients with viral hepatitis who are unresponsive to current antiviral therapies [8].

Many recent studies have defined the key role of renin-angiotensin-aldosterone system (RAAS) in the pathogenesis of hepatic fibrosis through activation of HSC, increasing the concentration of proinflammatory cytokines, Tumor necrosis factor alpha (TNF- $\alpha$ ), interleukin 1B (IL-1B), interleukin 6 (IL-6), Inducible nitric oxide synthase (iNOS), cyclooxygenase 2 (Cox2), transforming growth factor-beta (TGFbeta), collagen deposition and lipid peroxidation products $[9,10]$.

Several studies reported the hepatoprotective role of angiotensin converting enzyme (ACE) inhibitors and angiotensin II type 1 receptor blocker against development of hepatic fibrosis in animals $[11,12]$ and humans $[13,14,15,16]$ via reducing the proliferation of HSC or decreasing the synthesis of profibrotic molecules. However, little is known about the hepatoprotective effect of aldosterone receptor antagonist [17]. Thus, we aim in the present study to clarify the effect of eplerenone, a selective mineralocorticoid receptor antagonist, on thioacetamide-induced liver injury in adult male albino rats and the possible underlying mechanisms.

\section{Materials and Methods}

\subsection{Animals}

All the experimental procedures were carried out in accordance with the guide available from the interdisciplinary principles and guidelines for the use of animals in research, testing, and education, issued by the New York Academy of Sciences Ad Hoc Committee on Animal Research [18] and were approved by the local institutional animal ethical committee.

Thirty two pathogen free adult male albino Wistar rats, $6-8$ weeks old, weighing between $220 \mathrm{~g}$ and $250 \mathrm{~g}$, were obtained from experimental animal breeding farm (Helwan, Cairo) to be used in the study. Animals were housed in the Animal Laboratory at the Medical Research Center of physiology department, Benha Faculty of Medicine in plastic cages under standard laboratory conditions (12h light/dark cycle, 20 $25{ }^{\circ} \mathrm{C}$ and relative humidity $55 \%$ ).

The animals were given standard commercial diet tap water. The animal diet was purchased from (El-Nasr Company, Cairo, Egypt). It is composed of Fat 5\% [corn oil 5\%], carbohydrates $65 \%$ [corn starch $15 \%$ and sucrose $50 \%$ ], proteins $20.3 \%$ [casein 20\% and DL-Methionine 3\%], fiber $5 \%$, salt mixture $3.7 \%$, and vitamin mixture $1 \%$ [19].

\subsection{Chemicals}

Thioacetamide (TAA), eplerenone, xylazine and ketamine were purchased from (Sigma Aldrich, St. Louis, USA).

\subsection{Experimental design}

The rats were acclimatized in the previous conditions for one week then they were randomly divided into four groups ( $\mathrm{n}=8$ in each group).

Group I (Control group): Rats of this group were given free access to food and water.

Group II (Eplerenone group): Rats of this group were treated with eplerenone (4 $\mathrm{mg} / \mathrm{kg} /$ day) by oral gavage [20] for 4 weeks.

Group III (Thioacetamide group): Rats of this group were injected with TAA $(200 \mathrm{mg} / \mathrm{kg}$ body 
weight) intraperitoneally (i.p.) three times per week [21] for 4 weeks.

Group IV (Thioacetamide + Eplerenone group): Rats of this group were treated with eplerenone ( $4 \mathrm{mg} / \mathrm{kg} /$ day) by oral gavage together with thioacetamide injection $(200 \mathrm{mg} / \mathrm{kg}$ body weight i.p. three times per week) for 4 weeks.

\subsection{Sample collection}

At the end of the experiment, the rats were anesthetized by xylazine (10 $\mathrm{mg} / \mathrm{kg}$ body weight) and Ketamine (100 mg/kg body weight) then sacrificed by decapitation. A craniocaudal incision of about $2 \mathrm{~cm}$, parallel and slightly to the left of the sternum was made then a blunt curved forceps is then binged between the 5th and 6th ribs through the intercostals muscles. The gap is widened so that the rapidly beating heart becomes visible. Intracardiac blood sample was drawn from the right ventricle and were allowed to clot at room temperature then the sera were separated by centrifugation at $3000 \mathrm{rpm}$ for $15 \mathrm{~min}$ and stored at $-80^{\circ} \mathrm{C}$ for biochemical assessment liver enzymes and inflammatory markers.

The abdomen was opened and liver was removed. The left lobe of the liver is kept for histopathological examination while the right lobe is frozen at $-80^{\circ} \mathrm{C}$ for estimation of hepatic malondialdehyde (MDA), reduced glutathione (GSH) and superoxide dismutase (SOD) enzymes.

\subsection{Assessment of liver functions}

Liver function was determined by assessment of serum level of liver enzymes; alanine aminotransferase (ALT) and aspartate aminotransferase (AST) by commercial kits purchased from (Sigma Aldrich, St. Louis, USA) according to the calorimetric method described by Reitman and Frankel 1957. Values were expressed in U/L [22].

\subsection{Assessment of inflammatory markers}

Serum level IL-6 and TNF-a were determined using enzyme linked immunosorbent assay (ELISA) kits according to the manufacturer's instructions (RayBiotech Inc, $U S A)$. Results were expressed in $(\mathrm{Pg} / \mathrm{ml})$.

\subsection{Assessment of oxidative stress}

MDA, GSH and SOD commercial kits were obtained from (Antibodies Online, Germany). Frozen liver tissue from the right lobe of each rat was washed by cold isotonic saline then minced and homogenized in $0.25 \mathrm{M}$ sucrose, $10 \mathrm{Mm}$ Tris- $\mathrm{HCl}, 1 \mathrm{mM}$ ethylenediaminetetraacetic acid (EDTA) buffer at $\mathrm{PH} 7.4$ the centrifuged at $10.000 \mathrm{rpm}$ for 10 minutes. The supernatant was used for assessment of oxidative stress and antioxidant enzymes. Malondialdehyde, the last product of lipid breakdown caused by oxidative stress, was evaluated by the thiobarbituric acid reactive substance (TBARS) method and was expressed as $\mathrm{nmol} / \mathrm{mg}$ protein using UV-VIS spectrophotometer (Hitachi, Japan) at $535 \mathrm{~nm}$ according to the method described by Buege and Aust 1978 [23]. Antioxidant enzymatic activity was detected by measuring hepatic GSH and SOD. GSH was measured in $\mu \mathrm{mol} / \mathrm{g}$ protein using spectrophotometer at $405 \mathrm{~nm}$ according to the method described by Akerboom and Sies 1981 [24] while SOD was measured in U/mg protein using a spectrophotometer $560 \mathrm{~nm}$ according to the method described by Marklund and Marklund 1974 [25].

\subsection{Histopathological examination}

Thin slices of the left lobes of the liver of each rat were collected and kept for $48 \mathrm{hr}$ in a $10 \%$ formaldehyde solution. After paraffin embedding, tissues were sectioned ( $5 \mu \mathrm{m}$ in thickness) and stained with hematoxylin and eosin (H\&E) for histolopathological examination under a light microscope (original magnification: 200x) and images were captured with a Nikon microscope (Y-THS, Japan). The degree of necrosis was expressed as the mean of 10 non overlapping high power fields (HPFs) and classified on a scale of $0-5$ (no hepatocyte necrosis $=0$; necrosis in few hepatocytes $=1$; necrosis in more than $10 \%$ but less than $24 \%$ of hepatocytes $=2$; necrosis in more than $25 \%$ but less than $39 \%$ of hepatocytes $=3$; necrosis in more than $40 \%$ but less than $49 \%$ of hepatocytes $=4$ and necrosis in more than $50 \%$ of hepatocytes $=5$ ) [26]. 


\subsection{Statistical analysis}

All statistical analyses were performed using the program "Statistical Package for Social Sciences (SPSS) version 16" (SPSS Inc, Chicago, IL, USA). The data were represented as the mean \pm standard deviation (SD). Comparisons among groups, in all studied parameters, were analyzed by using One-way analysis of variance (ANOVA) test and Post Hoc multiple comparisons (LSD test). Probability of chance ( $\mathrm{P}$ value $)<0.05$ was considered statistically significant.

\section{Results}

Biochemical results of serum ALT, AST, IL6 and TNF-a as well as the hepatic oxidative stress markers are summarized in table 1 which shows that there is non-significant change in Serum level of ALT, AST, IL-6 and TNF-a, hepatic SOD activity, MDA or GSH content in rats treated with eplerenone alone when compared with the control group $(P>0.05)$. TAA injection resulted in significant increase in the serum level of ALT, AST, IL-6, TNF-a and hepatic content of MDA and significant decrease of hepatic GSH content and SOD activity $(P<$ 0.001). Coadminstration of eplerenone with TAA injection lead to significant decrease of the elevated levels of serum ALT, AST, IL-6 and TNF-a as well as hepatic content of MDA and significant increase in hepatic SOD activity and GSH content $(P<0.001)$.

Table 1: Biochemical serum parameters (ALT, AST, IL-6 and TNF-a) and hepatic oxidative stress makers (MDA, SOD and GSH)

\begin{tabular}{|c|c|c|c|c|}
\hline Groups & & & & \\
\hline Parameters & $\begin{array}{c}\text { (Control) } \\
n=8\end{array}$ & $\begin{array}{c}\text { (Eplerenone) } \\
n=8\end{array}$ & $\begin{array}{c}\text { (TAA) } \\
\mathbf{n}=8\end{array}$ & $\begin{array}{c}\text { (Eplerenone + TAA) } \\
n=8\end{array}$ \\
\hline $\operatorname{ALT}(\mathbf{U} / \mathbf{L})$ & $42.31 \pm 3.29$ & $43.12 \pm 1.96$ & $73.85 \pm 2.94^{*}$ & $43.13 \pm 0.82^{\dagger}$ \\
\hline $\operatorname{AST}(\mathbf{U} / \mathbf{L})$ & $175.68 \pm 1.62$ & $176.39 \pm 2.49$ & $291.75 \pm 21.86^{*}$ & $176.08 \pm 0.75^{\dagger}$ \\
\hline IL-6 (Pg/ml) & $39.04 \pm 2.40$ & $39.44 \pm 2.16$ & $162.82 \pm 3.24^{*}$ & $39.59 \pm 1.94^{\dagger}$ \\
\hline TNF- $\alpha(\mathrm{Pg} / \mathrm{ml})$ & $29.88 \pm 1.30$ & $29.95 \pm 1.48$ & $80.81 \pm 2.40^{*}$ & $30.13 \pm 0.99^{\dagger}$ \\
\hline MDA (nmol/mg protein) & $2.09 \pm 0.20$ & $2.15 \pm 0.19$ & $5.80 \pm 0.23^{*}$ & $2.11 \pm 0.18^{\dagger}$ \\
\hline SOD (U/mg protein) & $83.47 \pm 0.28$ & $84.23 \pm 0.98$ & $46.22 \pm 1.21^{*}$ & $83.54 \pm 1.26^{\dagger}$ \\
\hline GSH ( $\mu \mathrm{mol} / \mathrm{g}$ protein) & $56.89 \pm 0.65$ & $57.14 \pm 1.48$ & $41.51 \pm 1.56^{*}$ & $55.79 \pm 1.33^{\dagger}$ \\
\hline
\end{tabular}

Data is expressed as mean \pm standard deviation, $P$. value $=$ probability of chance, $P<0.05$ is significant tested by using One-way analysis of variance (ANOVA) test and Post Hoc multiple comparisons (LSD test).

* Significant difference vs the control group.

${ }^{\dagger}$ Significant difference vs the TAA group.

Table 2: Mortality rate and histopathological examination

\begin{tabular}{|c|c|c|c|c|}
\hline Groups & $\begin{array}{c}\text { Group I } \\
\text { Parameters }\end{array}$ & $\begin{array}{c}\text { Group II } \\
\text { (E) }=8\end{array}$ & $\begin{array}{c}\text { Group III } \\
\text { (TAA) } \\
\mathbf{n = 8}\end{array}$ & $\begin{array}{c}\text { Group IV } \\
\text { (Eplerenone + TAA) } \\
\mathbf{n = 8}\end{array}$ \\
\hline Mortality rate (\%) & 0 & 0 & 0 & 0 \\
\hline Histopathological grading & 0 & 0 & $4.15 \pm 0.37^{*}$ & $1.12 \pm 0.42^{\dagger}$ \\
\hline
\end{tabular}

Data of histopathological grading of liver necrosis is expressed as mean \pm standard deviation, $\mathrm{P}$. value $=$ probability of chance, $\mathrm{P}<0.05$ is significant tested by using One-way analysis of variance (ANOVA) test and Post Hoc multiple comparisons (LSD test). 
Mortality rate: No rats were died during the experimental procedures in all studied groups (mortality rate $=0 \%$ ) as shown in Table 2.

Histopathological grading of liver necrosis (Table 2 and Fig. 1) show that no lesion was detected in both group I (Control group) and group II (Eplerenone group). TAA injection (group III) caused significant increase in grading of liver necrosis as compared to group I and group II $(P<0.05)$. Coadminstration of eplerenone with TAA injection lead to significant decrease in grading of liver necrosis as compared to TAA group $(P<0.05)$.
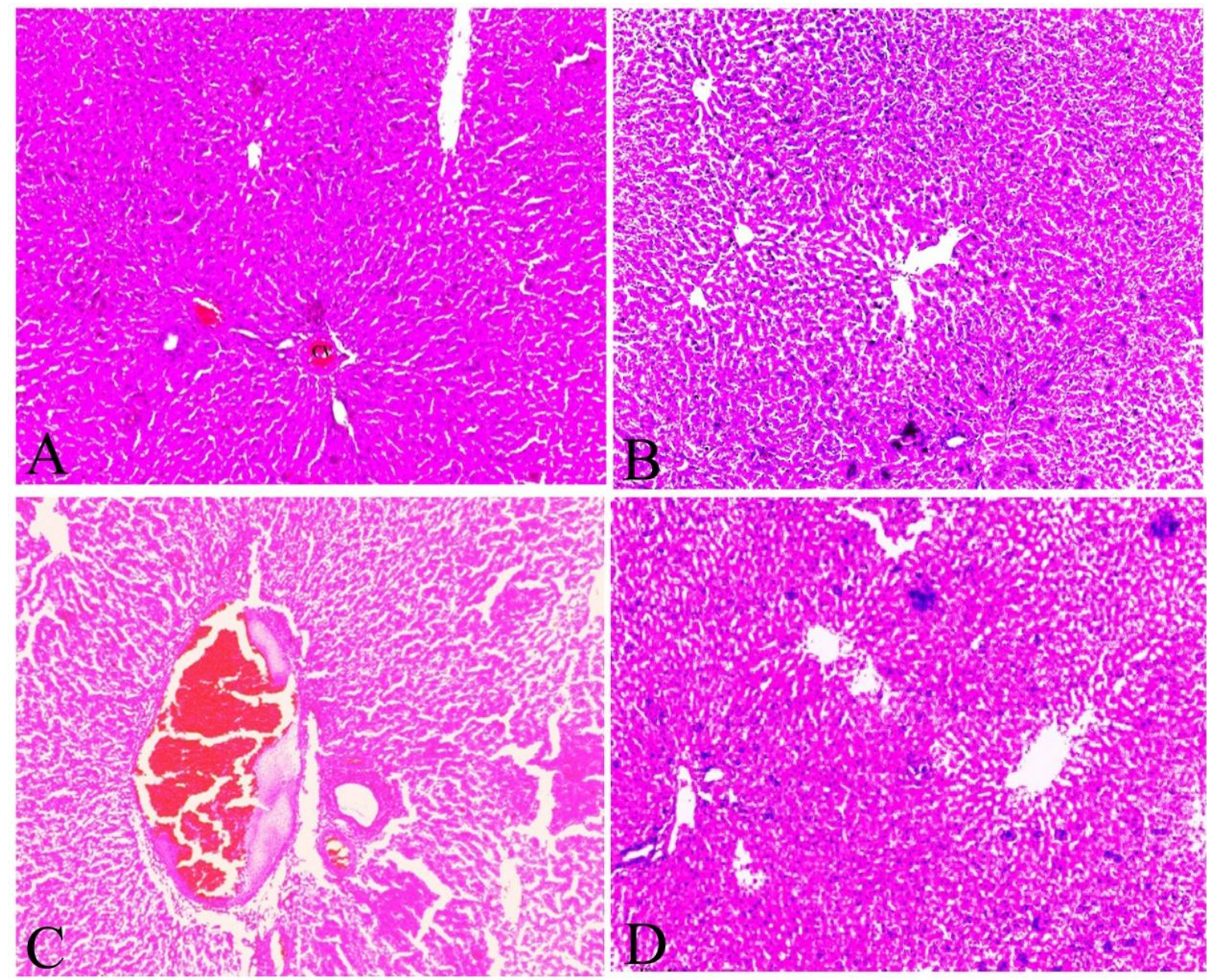

Figure. 1 (Histopathological examination): (A) The liver of rats of the control group (Group 1) showing normal lobular architecture with central vein $(\mathrm{CV})$ and radiating hepatic cords. The hepatocytes show well preserved eosinophilic cytoplasm arranged in strands around the central vein. (B) The liver of rats of group II (Eplerenone group) showing normal hepatic architecture with central vein and radiating hepatic cords. (C) The liver of rats of group III (TAA group) showing dilated and congested portal venule with perivenular necrosis and inflammatory cells infiltration. (D) The liver of rats of group IV (TAA + Eplerenone group) showing restoration of hepatocytes and less inflammatory cells infiltration (H\&E stain, original magnification: 200x).

\section{Discussion}

The present study investigated the effect of eplerenone on thioacetamide induced liver injury in adult male albino rats. Administration of eplerenone alone in rats has non- significant change on liver enzymes, inflammatory markers, hepatic oxidative stress markers. TAA injection resulted in liver injury as indicated by significant increase in serum level of liver enzymes; ALT 
and AST. It also enhanced oxidative stress as hepatic MDA content was found to be significantly elevated while hepatic antioxidant enzymes; GSH and SOD were found to be significantly decreased. Moreover, thioacetamide caused significant increase in IL- 6 and TNF- $\alpha$. These findings were confirmed by histopthological examination. The findings of the present study are congruent to the previous studies [21, 27, 28, 29]. Mechanisms participating in the development of TAA-induced liver injury have been intensively studied. Thioacetamide induces its hepatotoxic effect through its S-oxide metabolite, an unstable reactive metabolite, which initiates necrosis and generation of reactive oxygen species (ROS) [30, 31 , 32] followed by lipid peroxidation and glutathione depletion [32, 33, 34].

Activation of mineralocorticoid receptor by aldosterone was documented to increases oxidative stress through increasing reactive oxygen species (ROS) as well as reducing ROS scavenging capacity of the cells [20, 36, 37] via activation of nicotinamide adenine dinucleotide phosphate (NADPH) oxidase enzyme [38].

The current study demonstrates the potential effect of mineralocorticoid receptor blockage by eplerenone in attenuating the oxidative stress which may be due to its inhibitory effect on NADPH oxidase enzyme [38], inflammatory process by reducing elevated inflammatory markers, and restoring the GSH and SOD normal levels that play an important role in the antioxidant defense mechanisms. The antioxidant and anti-inflammatory effect of eplerenone play a key role in preserving the normal hepatocellular architecture and restoring the normal liver functions [20].

\section{Conclusion and Recommendations}

Eplerenone, a mineralocorticoid receptor antagonist provides a hepatoprotective effect against thioacetamide induced liver damage via reducing liver enzymes, oxidative stress and inflammatory process and improving antioxidant activity thus restoring normal live architecture. This indicates that aldosterone is implicated in induction of liver damage induced by thioactamide injection. However we recommend further studies to adjust the dose of epleronone in treating liver injury to avoid its adverse effects like hyperkalemia and hypotension.

\section{Abbreviations}

HSCs, Hepatic stellate cells; KCs, Kupffer cells; ECM, Extracellular matrix; BDL, Bile duct ligation; CCL4, Carbon tetrachloride; TTA, Thioacetamide; RAAS, Renin angiotensin aldosterone system; TNF- $\alpha$, Tumor necrosis factor alpha; IL-1B, interleukin 1B; IL-6, interleukin 6; iNOS, Inducible nitric oxide synthase; Cox2, Cyclooxygenase 2; TGF-beta, Transforming growth factor-beta; ACE, Angiotensin converting enzyme; i.p., Intraperitoneally; MDA, malondialdehyde; GSH, reduced glutathione; SOD superoxide dismutase; ALT, alanine aminotransferase; AST, aspartate aminotransferase; TBARS, Thiobarbituric acid reactive substance; EDTA, ethylenediaminetetraacetic acid; ELISA, enzyme linked immunosorbent assay; H\&E, Hematoxlin and eosin; ROS, Reactive oxygen species; NADPH, reduced nicotinamide adenine dinucleotide phosphate.

\section{Acknowledgment}

The author expresses deep appreciation to the staff members and technicians of physiology and pathology department, Benha Faculty of Medicine, Benha University for their valuable cooperation during the practical part of this work.

\section{References}

1. Friedman, S.L. Liver, Biliary tract and Pancreas, in: Current medical diagnosis and treatment, Tierney, L.M., Mcphee, S.J., Papadiakins, M.E. (Eds) $41^{\text {st }}$ Ed., Lange medical books, McGraw Hill, New York, 2002. Pp. 692.

2. Friedman, S. L.; Maher, J.J.; Bissell, D.M. Mechanisms and therapy of hepatic fibrosis: report of the AASLD Single Topic Basic 
Research Conference. Hepatology, 2000, 32, 1403-1408. doi:10.1053/jhep.2000.20243.

3. Friedman, S.L. Mechanisms of hepatic fibrogenesis. Gastroenterology, 2008, 134, 1655-1669. doi:10.1053/j.gastro.2008.03.003.

4. Friedman, S.L. Liver fibrosis - from bench to beside. J. Hepatol., 2003, 38(Suppl 1), S38-S53. PMID: 12591185.

5. Granzow, M.; Schierwagen, R.; Klein, S.; Kowallick, B.; Huss, S.; Linhart, M.; Mazar, I.G.; Görtzen, J.; Vogt, A.; Schildberg, F.A.; Gonzalez-Carmona, M.A.; Wojtalla, A.; Krämer, B.; Nattermann, J.; Siegmund, S.V.; Werner, N.; Fürst, D.O.; Laleman, W.; Knolle, P.; Shah, V.H.; Sauerbruch, T.; Trebicka, J. Angiotensin-II type 1 receptormediated Janus kinase 2 activation induces liver fibrosis. Hepatology, 2014, 60(1), 33448. doi: 10.1002/hep.27117. PMID: 24619965.

6. Bélanger, M.; Butterworth, R.F. Acute liver failure: a critical appraisal of available animal models. Metab. Brain Dis., 2005, 20(4), 409-23. PMID: 16382351.

7. Chilakapati, J.; Shankar, K.; Korrapati, M.C.; Hill, R.A.; Mehendale, H.M. Saturation toxicokinetics of thioacetamide: role in initiation of liver injury. Drug Metab. Dispos., 2005, 33(12): 1877-85. PMID: 16183780.

8. Trautwein, C.; Friedman, S.L.; Schuppan, D.; Pinzani, M. Hepatic fibrosis: Concept to treatment. J. Hepatol., 2015, 62(1S), S15S24. doi: 10.1016/j.jhep.2015.02.039. PMID: 25920084.

9. Munshi, M.K.; Uddin, M.N.; Glaser, S.S. The role of the renin-angiotensin system in liver fibrosis. Exp. Biol. Med. (Maywood), 2011, 236(5), 557-66. doi: 10.1258/ebm.2011.010375. $\quad \underline{\text { PMID: }}$ 21508249.

10. Bataller, R.; Gabele, E.; Parsons, C.J.; Morris, T.; Yang, L.; Schoonhoven, R.; Brenner, D.A.; Rippe, R.A. Systemic infusion of angiotensin II exacerbates liver fibrosis in bile duct-ligated rats. Hepatol., 2005, 41(5), 1046-1055. PMID: 15841463.

11. Ueki, M.; Koda, M.; Yamamoto, S.; Matsunaga, Y.; Murawaki, Y. Preventive and therapeutic effects of angiotensin II type 1 receptor blocker on hepatic fibrosis induced by bile duct ligation in rats. J. Gastroenterol., 2006 , 41(10), 996-1004.doi:

10.1007/s00535-006-1891-1. 17096069 .

12. Kurikawa, N.; Suga, M.; Kuroda, S.; Yamada, K.; Ishikawa, H. An angiotensin II type 1 receptor antagonist, olmesartan medoxomil, improves experimental liver fibrosis by suppression of proliferation and collagen synthesis in activated hepatic stellate cells. Br. J. Pharmacol., 2003, 139(6), 1085-94. PMID: 12871826 - PMCID: PMC1573934.

13. Reese, L.J.; Tider, D.S.; Stivala, A.C.; Fishbein, D.A. Effects of Angiotensin Converting Enzyme Inhibitors on Liver Fibrosis in HIV and Hepatitis C Coinfection. AIDS Res. Treat., 2012, 2012, 978790. doi: 10.1155/2012/978790. PMID: 23193466 PMCID: PMC3501811.

14. Ueki, M.; Koda, M.; Shimizu, T.; Mitsuta, A.; Yamamoto, T.; Murawaki, Y. Effect of an angiotensin-II type-1 receptor blocker, candesartan on hepatic fibrosis in chronic hepatitis C: a prospective study. Hepatogastroenterology, 2009, 56(93), 1100-4. PMID: 19760950.

15. Yokohama, S.; Yoneda, M.; Haneda, M.; Okamoto, S.; Okada, M.; Aso, K.; Hasegawa, T.; Tokusashi, Y.; Miyokawa, N.; Nakamura, $\mathrm{K}$. Therapeutic efficacy of an angiotensin II receptor antagonist in patients with nonalcoholic steatohepatitis. Hepatology, 2004, 40(5), 1222-5. PMID: 15382153.

16. Terui, Y.; Saito, T.; Watanabe, H.; Togashi, H.; Kawata, S.; Kamada, Y.; Sakuta, S. Effect of angiotensin receptor antagonist on liver fibrosis in early stages of chronic hepatitis C. Hepatology, 2002, 36(4 Pt 1), 1022. doi: 10.1053/jhep.2002.32679. PMID: 12297856.

17. Töx, U.; Steffen, H.M. Impact of inhibitors of the Renin-Angiotensin-aldosterone system on liver fibrosis and portal hypertension. Curr. Med. Chem., 2006, 13(30), 3649-61. doi: $10.2174 / 092986706779026138$. PMID: 17168728 . 
18. Ad Hoc Committee on animal research. Types of experiments, in New York academy of sciences interdisciplinary principles and guidelines for the use of animals in research, testing, and education. New York: New York Academy of Sciences, 1988, Appendix 1: Pp. 1a-1c.

19. Noeman, S.A.; Hamooda, H.E., Baalash, A.A. Biochemical Study of Oxidative Stress Markers in the Liver, Kidney and Heart of High Fat Diet Induced Obesity in Rats. Diabetol Metab Syndr. 2011, 3, 17. doi: $\quad 10.1186 / 1758-5996-3-17 . \quad \underline{\text { PMCID: }}$ PMC3174870.

20. Taye, A.; Abdel-Raheem, I.T. Hepatoprotective effect of the selective mineralocorticoid receptor antagonist, eplerenone agaist carbon tetarachlorideinduced liver injury in rats. Ann. Hepatol., 2012, 11(3), 384-391. PMID: 22481458.

21. Saleh, D.O.; Abdel-Jaleel, G.A.; El-Awdan, S.A.; Oraby, F.; Badawi, M. Thioacetamideinduced liver injury: protective role of genistein. Canadian Journal of Physiology and Pharmacology, 2014, 92(11), 965-973. doi: 10.1139/cjpp-2014-0192.

22. Reitman, S.; Frankel, S. Colorimetric method for determination of serum glutamic oxaloacetic and glutamic pyruvate transaminases. Am. J. Clin. Pathol., 1957, 28, 56-63. PMID: 13458125.

23. Buege, J.A.; Aust, S.D. Microsomal lipid peroxidation. Methods Enzymol., 1978, 52, 302-10. PMID: 672633.

24. Akerboom, T.P.M.; Sies, H. Assay of glutathione disulfide and glutathione mixed disulfides in biological sample. In: Methods in Enzymology. New York: Academic Press, 1981, Vol. 77, Pp. 373-382.

25. Marklund, S.; Marklund, G. Involvement of the superoxide anion radical in the autooxidation of pyrogallol and a convenient assay for superoxide dismutase. Eur. J. Biochem., 1974, 47(3), 469-474. PMID: $\underline{4215654 .}$

26. Bayomy. N.A., Elshafey, S.H., Mosaed, M.M., Hegazy, A.M.S. Protective Effect of Curcumin versus N-acetylcystein on Acetaminophen Induced Hepatotoxicity in
Adult Albino Rats. J. Cytol. Histol., 2015, S3: 018. doi:10.4172/2157-7099.S3-018.

27. Abdel Salam, O.M.; Mohammed, N.A.; Sleem, A.A.; Farrag, A.R. The effect of antidepressant drugs on thioacetamideinduced oxidative stress. Eur. Rev. Med. Pharmacol. Sci., 2013, 17(6), 735-44. PMID: 23609356.

28. de David, C.; Rodrigues, G.; Bona, S.; Meurer, L.; González-Gallego, J.; Tuñón, M.J.; Marroni, N. P. Role of quercetin in preventing thioacetamide-induced liver injury in rats. Toxicol. Pathol., 2011, 39(6), 949-57. doi: 10.1177/0192623311418680.

29. Mehmetçik, G.; Özdemirler, G.; KoçakToker, N.; Çevikbaş, U.; Uysal, M. Role of carnosine in preventing thioacetamideinduced liver injury in the rat. Peptides, 2008, 29(3), 425- 429. doi:10.1016/j.peptides.2007.11.008.

30. Baskaran, N.; Periyasam,V.; Venkatraman, A.C. Investigation of antioxidant, antiinflammatory and DNA-protective properties of eugenol in thioacetamide induced liver injury in rats. Toxicology, 2010, 268(3), 20412. doi:10.1016/j.tox.2009.12.018.

31. Pallottini, V.; Martini, C.; Bassi, A.M.; Romano, P.; Nanni, G.; Trentalance, A. Rat HMG CoA reductase activation in thioacetamide-induced liver injury is related to an increased reactive oxygen species content. Journal of Hepatology, 2006, 44, 368-374. PMID: 16140414.

32. Okuyama, H.; Nakamura, H.; Shimahara, Y.; Araya, S.; Kawada, N.; Yamaoka, Y.; Yodoi, J. Overexpression of thioredoxin prevents acute hepatitis caused by thioacetamide or lipopolysaccharide in mice. Hepatology, 2003, 37(5), 1015-1025. doi: 10.1053/jhep.2003.50203. PMID: 12717382.

33. Lotkova, H.; Cervinkova, Z.; Kucera, O.; Rousar, T.; Krivakova, P. SAdenosylmethionine exerts a protective effect against thioacetamide-induced injury in primary cultures of rat hepatocytes. Altern. Lab. Anim. (ATLA), 2007, 35(3), 363-371. PMID: 17650956.

34. Sanz, N.; Diez-Fernandez, C.; Andres, D.; Cascales, M. Hepatotoxicity and aging: 
endogenous antioxidant systems in hepatocytes from 2-, 6-, 12-, 18- and 30month-old rats following a necrogenic dose of thioacetamide. Biochimica et Biophysica Acta, 2002, 1587, 12-20. PMID: 12009419.

35. Zaragoza, A.; Andres, D.; Sarrion, D.; Cascales, M. Potentiation of thioacetamide hepatotoxicity by phenobarbital pretreatment in rats. Inducibility of FAD monooxygenase system and age effect. Chem. Biol. Interact., 2000, 124, 87-101. PMID: 10670821.

36. Matono, T.; Koda, M.; Tokunaga, S.; Sugihara, T.; Ueki, M.; Murawaki, Y. The effects of the selective mineralocorticoid receptor antagonist eplerenone on hepatic fibrosis induced by bile duct ligation in rat.
International Journal of Molecular Medicine, 2010, 25(6), 875-882. doi: 10.3892/ijmm_00000417.

37. Li, X.; Meng, Y.; Yang, X.S.; Wu, P.S.; Zhang, Z.S. Aldosterone stimulating PDGF$B$ expression in HSC via activation of EGR-1. Zhonghua Gan Zang Bing Za Zhi., 2005, 13(8):567-70. PMID: 16092976.

38. Park, Y.M.; Lim, B.H.; Touyz, R.M.; Park, J.B. Expression of NAD $(\mathrm{P}) \mathrm{H}$ oxidase subunits and their contribution to cardiovascular damage in aldosterone/saltinduced hypertensive rat. J. Korean Med Sci., 2008, 23(6), 1039-45. doi: 10.3346/jkms.2008. PMID: 19119450. 